\title{
¿Quiénes somos? Construyendo identidades desde la investigación
}

para la paz

Who Are We? Building Identities from the Perspective of Peace Studies

Juan Manuel Jiménez Arenas* Universidad de Granada, Granada, España http://orcid.org/0000-0002-4165-0187

Artículo de investigación

Fecha de recepción: 29 de febrero de 2020 Fecha de aceptación: 15 de abril de 2020

\section{Para citar este artículo}

Jiménez Arenas, J. (2020). ¿Quiénes somos? Construyendo identidades desde la investigación para la paz. Campos en Ciencias Sociales, 8(2), 17-46. Dor: https:// doi.org/10.15332/25006681/6011

* Profesor titular del Departamento de Prehistoria y Arqueología y director del Instituto Universitario de la Paz y los Conflictos de la Universidad de Granada, Granda, España; coordinador del proyecto orce sobre las primeras ocupaciones humanas en el continente europeo. Correo electrónico: jumajia@ugr.es 


\section{RESUMEN}

Las identidades o, para ser más imprecisos, las relaciones de pertenencia son una característica que es perceptible en todas las entidades humanas; tradicionalmente, se ha planteado su naturaleza diferenciadora y excluyente. No obstante, desde la investigación para la paz - concretamente desde la doble perspectiva de la paz imperfecta y los giros epistemológico y ontológico- y dialogando con la complejidad y la transmodernidad, planteamos que otras formas de concebir las identidades no solo son posibles, sino que ya existen. Para ello, hemos de preguntarnos cómo somos los seres humanos y cómo concebimos el poder. Desde una perspectiva crítica radical que nos permite la investigación para la paz, podemos interpretar que los(as) otros(as) forman parte consustancial del nosotros(as). Partiremos de que las identidades son construcciones sociales que se pergeñan dentro de un marco sistémico para condicionar los roles mediante los cuales los diferentes actores orientan sus representaciones y sus acciones. Esto nos permite resaltar que el carácter excluyente, jerárquico y estanco no es consustancial a las identidades. Como metáforas utilizaré la de las identidades-amalgamas y la de las identidades-caleidoscopio: identidades complejas, rizomáticas, basadas en lo que nos hacemos, conscientes de la diferencia, pero que evitan la desigualdad.

Palabras clave: paz imperfecta, giro epistemológico, ontología, transmodernidad, complejidad, pertenencia.

\section{Abstract}

Identities or, more loosely, relationships of belonging, are a perceptible feature in all human entities. Traditionally, their differentiating and exclusionary nature has been raised. However, from peace studies - specifically, from the dual perspective of imperfect peace and the epistemological and ontological turns - and in dialogue with Complexity and Transmodernity, we argue that other ways of conceiving identities are not only possible, but already exist. To this end, we must ask ourselves what we human beings are like and how we conceive power. Rooted in the critical and radical perspective opened up by peace studies, we can interpret that others (otros/as) are an integral part of us (nosotroslas). We will start from the fact that identities are social constructions rooted in a systemic framework which conditions 
the roles through which the different actors guide their representations and actions. This allows us to emphasize that the exclusionary, hierarchical, and watertight character of identities is not inherent to them. To illustrate this proposal, we use two metaphors, that of identities-amalgams and that of identities-kaleidoscope: complex and rhizomatic identities, based on what we do and aware of differences, but avoiding inequality.

Keywords: imperfect peace, epistemological turn, ontology, transmodernity, complexity, belonging.

\section{INTRODUCCIÓN}

En un mundo cambiante, como el que vivimos mientras se termina de producir este texto, podemos adoptar dos posiciones generales que dieron título a uno de los más celebrados libros de Umberto Eco: la apocalíptica, "nutrido por la desconfianza total en cualquier acción que pueda modificar el orden de las cosas" (1993, p. 30); o la integrada, que apuesta por "la adecuación del gusto, y del lenguaje, a la capacidad receptiva media" (p. 31), “conservadores amargados” o "progresistas en acción” (p. 13). Ante este orbe globalizado que se cierne (probablemente) más incierto que nunca, el sentido general de eso que hemos dado en llamar identidad, presenta un conflicto tan palpable como el expuesto por el filósofo piamontés. No obstante, como trataré de explicar a lo largo de este artículo, dicha tensión no es real, porque la identidad que, para los apocalípticos es homogénea y quasi inmutable, emerge en su propia consideración entreverada, híbrida, espuria. Si la identidad se ha referido, básicamente, al nosotros frente a los otros, desde estas páginas apostaremos por un nosotros del que los otros forman parte consustancial. La identidad, las identidades, son fruto de la hibridación permanente y presentan elementos fundamentales que, incluso, han sido préstamos de comunidades y colectivos que han sido marginalizados por los hegemónicos. Estos, de paso, se han apoderado de las prácticas de aquellos, resignificándolas. 
Obviamente, este escrito no pretende hacer un recorrido arqueológico por el concepto de identidad; esa inmensa tarea supera con creces los objetivos de la presente propuesta. Se trata, pues, de aplicar el doble difusor de la paz imperfecta ${ }^{1}$ (Muñoz, 2001) y el giro epistemológico² (Martínez Guzmán, 2001) — trocado a ontológico — - y comenzar un diálogo coral a la luz de la complejidad y la transmodernidad para preguntarnos: ¿son violentas las identidades o también pueden ser - y son — pacíficas?

1 Aunque a lo largo de las próximas páginas desarrollaré la idea de paz imperfecta en relación con las identidades, aquella es una conceptualización de la paz que surge a principios de este siglo de la mano de Francisco Muñoz Muńoz, catedrático de Historia Antigua y fundador del Instituto Universitario de la Paz y los Conflictos de la Universidad de Granada. Emerge como una propuesta alternativa a las paces negativa y positiva. En palabras de Muñoz (2001), surge como el desarrollo de las capacidades deseables de los seres humanos; se destaca por ser inacabada, en permanente construcción, procesual y cotidiana, y que emerge como una responsabilidad ética de todos. Por ende, para que haya paz no es necesario que desparezca la violencia. Como característica ańadida resalta que se trata de una paz independiente de la violencia, puesto que es consecuencia de los conflictos. Esto permite plantear que la inmensa mayoría de los conflictos que los humanos hemos encarado a lo largo de nuestra historia se han transformado de manera pacífica. Es más, desde una perspectiva evolutiva, podemos plantear que los comportamientos cooperativos, solidarios y altruistas han sido clave para los éxitos de nuestros antepasados; también en el presente. Así, la paz es una respuesta optimizada a la complejidad de los seres humanos fruto de la inmensa cantidad y calidad de conflictos con los que convivimos (Jiménez Arenas, 2011; 2018; 2020).

2 Para ilustrar el significado de giro epistemológico recurro a las palabras del propio Vicent Martínez Guzmán (2001):

Los Estudios para la Paz, junto con la explicitación de los sesgos de género implícitos en la metodología pretendidamente neutral de la ciencia moderna, la recuperación de saberes autóctonos sometidos al poder del saber de esa ciencia, considerado único y universal y las críticas posmodernas a la modernidad, producen convulsión en la noción de ciencia heredada de la modernidad que nos ayuda a entendernos de maneras diferentes sobre las múltiples formas en que los seres humanos podemos desaprender las guerras, violencias y exclusiones y aprender a hacer las paces. (p. 76)

En definitiva, se trata de "dar un giro epistemológico para no centrar nuestras investigaciones sobre la guerra [y otras formas de violencia] sino sobre la paz," reuniendo información sobre indicadores para hacer las paces desde una perspectiva transdisciplinar (Martínez Guzmán, 2001, p. 143 y ss.).

3 El giro ontológico implica ir más allá de lo epistemológico, puesto que la consideración del ser humano fertiliza el cómo sabemos. En este sentido, la incorporación de lo ontológico al giro conlleva la ampliación y el cuestionamiento de los fundamentos del ser de lo ente (Heidegger, 2016, p. 5). En el caso de los humanos, es capital entender que lo ontológico no es ni lo violento ni lo pacífico, sino lo conflictivo (Millán Campuzano, 2015, p. 2). 


\section{¿QUÉ ES LA IDENTIDAD?}

Si preguntamos qué es la identidad, las respuestas serán múltiples y diversas. No obstante, coinciden una serie de características que deben ser consideradas fundamento de esta. En primer lugar, que se trata de construcciones sociales. En palabras de Simone de Beauvoir: "No se nace mujer, ser llega a serlo" (2005, p. 381). Esto implica la desnaturalización de lo que somos. Sin embargo y a pesar de lo expuesto, las últimas décadas han supuesto una recuperación del componente biológico y su interacción con otros elementos, incluidos los discursivos, tal y como ha puesto de manifiesto Elisabeth Grosz (2004). En segundo lugar, que las identidades tienen una vertiente aglutinadora, vertebradora, a la vez que diferenciadora. Ahora bien, el hecho de que destaque las diferencias, estas no se deben convertir en argumentos de justificación y legitimación de las desigualdades. En tercero, que la identidad pretende orientar las formas de estar en el mundo y las acciones derivadas de estas. Así las cosas, tiende a converger con el concepto bourdiano de habitus (Bourdieu, 1972, p. 178). Empero, desde estas páginas defenderé que la capacidad de agencia —aunque constreñida por condicionantes estructurales - también contribuye, o debería contribuir, a la configuración de las identidades (Brown, 2017; Currie et al., 2010; Skovgaard-Smith et al., 2019; Ybema et al., 2009). Las estructuras condicionan, pero permiten márgenes suficientes de acción. Al hilo de la diferencia entre el permitir y el deber permitir, me gustaría introducir una cuestión fundamental para el entronque de la identidad con la investigación para la paz: el carácter ético y moral de aquella que destacan autores como Taylor (1996, p. 10 y ss.).

La relevancia de la identidad y la pertenencia llevó a Heidegger a plantear si estas son rasgos de los seres humanos o fundamentos de lo ente (Heidegger, 2016, p. 91). El filósofo alemán se decantó por lo segundo para, de esta forma, elevarla a la esfera de la ontología. El carácter filosófico de la identidad tampoco forma parte de los objetivos de este trabajo, aunque cual sea nuestra concepción del ser humano en cuanto ente, va a tener una influencia fundamental en la consideración y tratamiento del concepto central que preside el presente artículo.

Aunque, como he adelantado, la identidad es un rasgo cultural y, por ende, colectivo, hay autores —entre ellos Taylor (1996) - que diferencian entre identidades 
individual y colectiva. En mi opinión y con el fin de clarificar terminológicamente esta cuestión, distinguiré entre personalidad e identidad. Por supuesto, las experiencias personales desempeñan un papel fundamental en la configuración de las identidades, pero no deja de ser menos cierto que se trata de una de las piezas que contribuyen al entramado de la identidad y que forma parte de la esfera de las elecciones que interaccionan con los roles asignados (Luyckx et al., 2006; Gibernau, 2017, p. 31).

Sobre el origen del concepto identidad, son múltiples los autores que han resaltado el carácter moderno de este (Heidegger, 2016 y referencias allí contenidas) diferenciándolo de la complementariedad jerárquica (Taylor, 1996, p. 17) propia de tiempos pretéritos o sociedades ancestrales. La identidad, o quizás la pertenencia — siendo más imprecisos, aunque más integradores-, es una característica que podemos considerar actualmente como universal. Desde un punto de vista evolutivo, no tenemos constancia del momento en el que surge; no obstante, y de manera muy genérica, podemos plantear que la diferenciación social en función del sexo, la edad o el acceso a determinadas actividades o bienes vino acompañada del reconocimiento de la disimilitud. Sin embargo, y esto es fundamental, dichos procesos no necesariamente debieron generar desigualdad (Jiménez-Arenas, 2018, 29; Skovgaard et al., 2019). En este debate, los modelos ontológicos de los que participemos van a condicionar nuestro concepto de identidad, así como el de poder y de la consideración de enemigo o adversario del otro. En líneas generales, existe una tendencia, moderna, a pensar la identidad como una característica de los seres humanos que es unitaria, excluyente y polarizante, que considera a ellos, a los otros como enemigos.

La identidad, en opinión de Eric Hobsbawm, presenta un carácter estratigráfico en el que diferentes capas superpuestas se apilan y de las que cada individuo destaca la(s) le pueda interesar en un momento dado (1994, p. 5). No obstante, existe una jerarquización en la que la identidad nacional, homogeneizadora y estandarizante (p. 8) tiende a predominar, convirtiéndose en monoétnica, monolingüística y monocultural (p. 14). Esta cuestión es ampliamente debatible y sorprendente, sobre todo teniendo en cuenta que si por algo se destaca Hobsbawm es por su labor como historiador, puesto que son reconocibles estados multiétnicos, multilingüísticos y multiculturales; entre muchos, Colombia. Lo que sí comparten todos los 
Estados-nación es la percepción de un pasado común (véase, por ejemplo, Renan, 2001). Sea como fuere, desde el giro epistemológico debemos ser más proclives a pensar las identidades tal y como las propone Amin Maalouf: como una creación única en la que no se pueden separar los elementos que la componen (2001, p. 2).

Stets y Burke realizan una interesante diferenciación entre identidades basadas en grupos (in-group based identities) y basadas en roles (in-role based identities) (2000, p. 226 y ss.). Considerando las primeras, estos autores asignan las siguientes características: uniformidad de percepción y acción; creación de estereotipos sociales y exclusión; tendencia a no cuestionar las decisiones del grupo; y establecimiento de relaciones paralelas. Respecto a las segundas, las fundamentan en la negociación y la interacción, las relaciones recíprocas y la singularidad interconectada.

Por su parte, Foucault propone que cualquier

[...] forma de poder se ejerce sobre la vida cotidiana inmediata que clasifica a los individuos en categorías, los designa por su propia individualidad, los ata a su propia identidad, les impone una ley de verdad que deben reconocer y que los otros deben reconocer en ellos. Es una forma de poder que transforma a los individuos en sujetos. hay dos significados de la palabra sujeto: sometido a otro a través del control y la dependencia y sujeto atado a su propia identidad por la conciencia o el conocimiento de sí mismo. Ambos significados sugieren una forma de poder. (Foucault, 1988, p. 7)

Sin embargo, tomando la crítica al concepto de poder que hace Arendt (1970), esto es violencia; por lo tanto, hay formas de identidad que son violentas. Siguiendo esa misma asunción, Cucagna y colegas van más allá al reconocer que:

La alteridad funciona como una operación de distinción entre semejanzas y diferencias que designa y ubica a "otros" desde la perspectiva de un "yo" o un "nosotros". Por medio de una disyunción, la alteridad establece un vínculo entre identidades y llega a naturalizar la relación entre ellas. (Cucagna et. al., 2007, p. 60) 
Ahora bien, como ha puesto de manifiesto Hernández Castellanos, alteridad nombra a todo lo otro que ha sido sometido por la identidad de lo mismo (2011, p. 16). Este carácter de dominación tampoco se aviene bien con la perspectiva del giro epistemológico aplicado a la investigación para la paz.

Otro concepto feraz dentro de los estudios sobre identidad ha sidolainterseccionalidad. Aunque inspirado en el trabajo de Angela Davis, diez años antes (1981), fue propuesto por Kimberle Crenshaw en 1991 y parte de que la violencia que sufren muchas mujeres se debe a veces a otras dimensiones de sus identidades tales como la raza o la clase social (1991, p. 1242). A las violencias ejercidas contra las mujeres, por el hecho de serlas, hay que ańadir las marginaciones sufridas por la concurrencia de otras características que, como la raza (población) y clase social, sirven como argumento para el ejercicio de la dominación. Como se puede comprobar fácilmente, el componente violento es intrínseco a la interseccionalidad. Incluso en trabajos sobre paz territorial en Colombia, el sesgo violentológico predomina (Iza Certuche, 2017).

Desde la interseccionalidad, las identidades se constituyen en elementos que, mayoritariamente, participarían de la violencia cultural (Galtung, 1990) y del poder simbólico (Bourdieu, 1991) que marginan y ocultan sentidos de pertenencia que, no pocas veces, claman venganza (Maalouf, 2001, p. 26); identidades que matan (p. 30). Por lo tanto, urge aplicar la paz imperfecta y el giro epistemológico; y, sin negar la existencia de este tipo de prácticas, visibilizar otras formas de identidad y poner de manifiesto la consideración de los otros como parte constituyente del nosotros. Para ello nos podemos valer de la propuesta derridiana: "La alteridad del otro, cuyo significado último es, precisamente, no el anular su diferencia, sino más bien mostrar que 'el otro', en cuanto alteridad, se inscribe en el mismo gesto en y desde uno mismo” (Madrid, 2008, p. 112; véase también Derrida, 1997, p. 97). Lo conectivo, las preposiciones en y desde, cobran especial relevancia.

Las identidades pueden tener, también, un carácter inclusivo; esto las dota de un carácter complejo y dialógico establecido entre los aspectos exo- y endo-. Es más, desde el giro epistemológico y ontológico vinculado a la paz imperfecta, se valora el reconocimiento y realce de la diversidad como camino hacia la equidad. 
Para ello es fundamental entender que las entidades humanas somos el resultado de una compleja combinación de características identitarias: móviles, inestables, heterogéneas, presentes, imperfectas (Garcés Montoya, 2005), que conviven bajo un discurso ficticio de unicidad (Vila, 2001).

\section{COMPLEJIDAD, TRANSMODERNIDAD Y TRANSDISCIPLINARIEDAD}

La propuesta de identidad que voy a pergeñar parte de la complejidad, la transmodernidad y la transdisciplinariedad. Entre las aperturas interpretativas que la complejidad nos ofrece se destacan la convivencia de hechos, acciones, determinaciones, indeterminaciones, certidumbres, incertidumbres, azares, caos y contextos en los que se producen y desarrollan los fenómenos que podemos percibir (Morin, 1998, p. 59-60) ${ }^{4}$. En otras palabras, desde las ideas sobre complejidad

4 Complejidad, a veces, se sinonimiza con enrevesado e incluso inasible. Por ello, es fundamental contar con buenas herramientas metodológicas. En el caso de la paz imperfecta, la propuesta es la matriz unitaria y comprensiva que se articula con cinco ejes que permiten abordar, mediante una agenda investigativa y de manera dialógica, la paz como categoría de análisis:

1. La consideración abierta y positiva de los conflictos. A partir de los trabajos de Muñoz y colaboradores(as) (sobre todo: Muñoz, 2001; Muñoz Muñoz y Molina Rueda, 2010; Jiménez Arenas y Muñoz Muñoz, 2013) se cuestiona que los conflictos sean sinónimo o antesala de la violencia. Se plantea que resultan de las diferencias en las percepciones, objetivos y desarrollo de capacidades entre agentes humanos; y, siguiendo a Vicenç Fisas, se deben considerar "un proceso interactivo que se da en un contexto determinado. Es una construcción social diferenciada de la violencia” (1998, p. 185). Así, del conflicto emanan la creatividad y las oportunidades, abriendo la posibilidad al cambio y a la transformación.

2. La paz imperfecta, de la cual ya se habló.

3. La visibilización y crítica de las violencias. Sin la existencia de la violencia no tendría sentido la investigación para la paz. Por violencia considero todas las "conductas o situaciones que, de forma deliberada, aprendida o imitada, provocan o amenazan con hacer daño o sometimiento grave (físico, verbal o psicológico [emotivo-cognitivo]) a las entidades humanas (desde individuos a la especie) y/o a los entornos y contextos en los que establecen sus interrelaciones para el desarrollo de sus capacidades, impidiéndolas o limitándolas en el presente y/o en el futuro" (Jiménez Arenas, 2018, p. 22).

4. Las mediaciones entendidas como una tercera parte que actúa en un conflicto. Tienen una dimensión topológica (de lugar) y gnoseológica (de cómo conocemos).

5. El empoderamiento y la agencia pacifistas. Es el nexo entre teoría y práctica, y nos lleva a la toma de conciencia de la capacidad que tiene el desarrollo de las capacidades humanas para transformar la realidad y su materialización mediante la acción (Jiménez Arenas, 2020). 
(Wagensberg, 1985) se apunta a que el resultado de la interacción entre diferentes identidades es distinto a la suma de los elementos que las constituyen (Stets y Burke, 2000; Maalouf, 2001; Keddell, 2009).

No obstante, y aún siendo importante en la caracterización de las identidades, considero que desde la perspectiva de la investigación para la paz debemos dar un paso más. Para ello recurriremos a otra característica indisoluble de la complejidad: la paradoja, la convivencia de aspectos aparentemente antagónicos (Muñoz, 2001; Jiménez Arenas, 2018). De esta manera podemos contribuir a evitar dos características muy de la concepción moderna de las identidades: la polarización y la jerarquización. Sin embargo, los últimos ańos han supuesto un auge de las identidades simplistas, mecanicistas, lineales, teleológicas y dogmáticas ${ }^{5}$, que participan de características de la complementariedad jerárquica premoderna (Taylor, 1996, p. 16). En esta concepción se apunta a que algunas identidades humanas tienen más dignidad que otras (1996, p. 17). Como alternativa de la complejidad podemos recurrir al pensamiento rizomático de Deleuze y Guattari: las identidades se construyen sin subordinaciones ni jerarquías (2008, p. 12). La transferencia se convierte en lo realmente importante, sobre todo si partimos del concepto hologramático de la realidad, que resalta el todo incluido en la parte que conforma al todo (Morin, 1998, p. 107 y ss.). Teniendo en cuenta lo antedicho en el presente parágrafo, en las identidades conviven aspectos aparentemente antagónicos, como pueden ser diferentes sentidos de pertenencia nacionales, de género, de estatus social, económico, etc. No es solo una adición, como propone Hobsbwam (1994), ni el fruto exclusivo de la discriminación (Crenshaw, 1991); tampoco asesinas (Maalouf, 2001); las identidades, por su carácter imperfecto, permiten la construcción de paz.

Lo imperfecto también remite a lo inacabado, (Muñoz, 2001), lo transformativo. Para ello es fundamental considerar una visión dinámica de las identidades, con formas cada vez más abiertas y que se entretejen formando una red. La transmodernidad

La metáfora de matriz remite tanto a la fisiología (órgano femenino de la gestación) como a las matemáticas (ordenación multidimensional de elementos).

5 Basta con echar un vistazo al panorama político internacional para notar la proliferación de partidos y políticos de marcado cariz populista y extremista. 
apunta a generar la flexibilidad y capacidad de transformación teórico-metodológica para ir dotando de respuestas satisfactorias a un mundo en constante cambio.

Las identidades transmodernas se constituyen desde la conciencia de cambio y surgen como proyectos de sistematización de las relaciones entre las tramas y las urdimbres. Desde la propuesta de transmodernidad que defendemos no se puede establecer una prevalencia de unos niveles sobre otros. Dicho de otro modo, todos los aspectos son relevantes en la configuración de las identidades. Los factores biológicos, los materiales, los sociales, los culturales, los prejuicios, los discursos..., todos interaccionan de manera que, como se ha comentado, hacen surgir características diferentes a las propias de los elementos originales. La transmodernidad, por lo tanto, critica, visibiliza los aspectos violentos; pero no solo esto, también cuenta con el ánimo de reconstruir desde una perspectiva pazológica. “'Trans' es transformación [más allá del estatismo de las esencias], dinamismo [sustancial], atravesamiento de algo en un medio diferente" (Rodríguez Magda, 2007). Para ello es fundamental establecer diálogos transversales e igualitarios en los que las epistemologías tiendan a la apertura (coexistencia de tendencias heterogéneas). "Su clave no es el post, la ruptura, sino la transubstanciación vasocomunicada de los paradigmas" (Rodríguez Magda, 2011, p. 6). La investigación para la paz debe convertir a las entidades humanas en agentes críticos que, desde el reconocimiento, cuestionen aquellas identidades que no promueve, e incluso impiden el desarrollo de las capacidades humanas deseables (Sánchez Cazorla, 1997, p. 15), y construyan presentes más equitativos y dignos.

El azar, entendido como la susceptibilidad a las condiciones iniciales (Ruelle, 1993, p. 53), también contribuye a la caracterización de las identidades. Esto es clave para entender el núcleo de la paz imperfecta y su relación con las identidades: no es necesario cambiarlo todo, porque cambiando algo ya estamos incidiendo en el todo. Ocurre que los modelos ontológicos negativos del ser humano provocan la prevalencia de sesgos violentológicos que afectan la manera cómo pensamos las identidades.

La ontología, aplicada a la concepción del ser humano en abstracto, va a tener una relevancia en la construcción de las identidades puesto que, siguiendo a Ernest Husserl, 
trata de aquellas esencias que convienen a todas las demás, las denominadas esencias formales (Ferrater Mora, 2001, p. 2625). Así las cosas, los caminos de legitimación y justificación de determinados discursos sobre las identidades humanas recurren a las supuestas esencias de los seres humanos. La influencia de la ontología en la práctica parece clara; pero lo es menos la conciencia de cómo nosotras(os) participamos en su afianzamiento o debilitamiento mediante nuestra práctica investigadora. Por lo tanto, ambas se retroalimentan, dando cuenta de otra de las características de la complejidad: la recursividad (Morin, 1991, p. 106-107).

A priori se pueden proponer dos grandes grupos de modelos ontológicos: uno, el negativo del ser humano, cuyo defensor más invocado es Thomas Hobbes y su "el hombre es un lobo para el hombre"; y otro, el positivo, cuya figura más representativa es Jean Jacques Rousseau y el denominado "mito del buen salvaje". Como es bien conocido, la mayor parte de los grandes metarrelatos modernos (liberalismo, marxismo, darwinismo, darwinismo social, sociobiología...) han participado de la propuesta ontológica negativa.

Ahora bien, desde la perspectiva que se viene proponiendo en el concepto de paz imperfecta, los seres humanos no somos ni esencialmente violentos, ni esencialmente pacíficos (Martínez Fernández y Jiménez Arenas, 2003); somos primariamente conflictivos (Muñoz, 2001). Lo ontológico, desde el punto de vista de la paz imperfecta, no es la violencia o la paz, es el conflicto. Por lo tanto, urge un modelo ontológico imperfecto que fije su atención en la caracterización del ser humano y que abandone las esencias y los binomios conceptuales (Jiménez Arenas, 2011; 2018).

El esencialismo necesita de fuentes demiúrgicas, un tiempo-no-tiempo en el que se fijan características que son importantes para la manera que tenemos de representarnos en un determinado grupo ${ }^{6}$; en esto converge con los mitos. Como consecuencia, las identidades esencialistas resultan transhistóricas: presentes atemporales con pretensión de ser presentes históricos; atraviesan el tiempo sin verse afectadas por las contingencias, por lo mudable. Son, "unidades de destino en lo universal" y, como

6 Esta podría ser una definición de identidad. 
tales, convierten en absolutos, que, empero, son gestados en un contexto específico y con unas intencionalidades concretas. Las identidades se valen, pues, del pasado y de la historia.

Ahora bien, es fundamental reconocer que dicha disciplina recurre a tres figuras retóricas de uso muy extensivo: la metáfora, la metonimia y la sinécdoque. De la primera destacaremos que la analogía ha sido fundamental para crear hiperrealidades, en el sentido en el que las propone Baudrillard (1978, p. 57). Las segundas, mediante el recurso al eufemismo, nombrando de manera diferente a los originales procesos, contextos, acciones, etc. —véase Arendt (1970, p. 41) para la diferenciación entre violencia y poder-. El tercero, implica que una parte - que incluso no tiene que ser real, puesto que puede incluir la metáfora y la metonimia - pretende representar al todo (Jiménez Arenas, 2018). De esta manera, la hábil mano del historiador puede, en primer lugar, elegir qué incluir dentro de su relato y, en segundo, hilvanar hechos inconexos para darles una apariencia de continuidad. Aparte de las tres figuras aludidas, el recurso a la hipérbole resulta fundamental para la configuración de identidades esenciales. Para todo ello, desde un punto de semántico y semiológico, con consecuencias sobresalientes en aspectos epistemológicos y ontológicos, descuella el uso del verbo $s e r$.

Por último, los modelos ontológicos se constituyen en andamiajes de los prejuicios y estos se alimentan de aquellos. No obstante, se trata de caracterizar a los seres humanos —evitando en la medida de lo posible y siendo conscientes de que los prejuicios son inherentes a nuestra práctica- con esos prejuicios preñados de violencia simbólica que, con más frecuencia de lo deseable, proliferan:

a. Antropocentrismo: el ser humano, culmen de la naturaleza.

b. Etnocentrismo: la persona analiza e interpreta en función de su cultura.

c. Androcentrismo: el hombre, medida de todas las cosas.

d. Biocentrismo: el ser humano, violento por naturaleza. 
Por lo tanto y para una identificación pacífica, consideraremos a los seres humanos como entes conflictivos, complejos, frágiles y poderosos, capaces de hacer las paces y de infligir violencias, aunque habituados a los cuidados (Comins Mingol y Jiménez Arenas, 2019).

\section{IDENTIDAD, PODER Y AGENCIA (PARA LA PAZ)}

Las concepciones de identidad y poder están íntimamente relacionadas (Foucault, 1988, p. 7). La doble propuesta de Stets y Burke (2001), ya comentada, resalta que las características en las identidades basadas en grupos son definidas por unos pocos, erigidos en líderes autocráticos (Dugas y Kruglanski, 2018, p. 73), quienes imponen una visión de cómo estar en el mundo, percibirlo y actuar en él. Por lo general, se trata de narrativas muy simplistas que pretenden otorgar una idea ilusoria de estabilidad, y que evitan el disenso por considerarlo como un camino para la erosión de la necesaria jerarquía (Dugas y Kruglanski, 2018, p. 74). Esta emerge como un término íntimamente relacionado con un poder que es necesariamente represor (Foucault, 1980 , p. 135). No obstante, existen, como se ha puesto de manifiesto en trabajos anteriores, otras concepciones del poder reconciliadas con la paz (Valencia Londoño et al., 2017; Jiménez Arenas, 2020) y, por ende, con la consideración pacífica de las identidades. Así las cosas, entender el poder de forma exclusivamente vertical, exógena, coercitiva y exclusivista ha sido cuestionado por diversos pensadores.

El primer autor que remite a una consideración del poder como generación de bienestar es John Locke, para quien el poder recae en el respeto y mantenimiento de las leyes comunes y el Estado - que es la institución a la que los ciudadanos ceden libremente ${ }^{7}$ su poder y, si se excede o no cumple con su parte del contrato, se le puede pedir cuentas-. Es más, el Estado está obligado a poner los medios para que el poder no se ejerza de forma sesgada y, por lo tanto, fraudulenta (Locke, 2013).

El poder puede ser sustantivo y verbo. En mi opinión, la segunda consideración es más fértil, porque indica acción, capacidad; siendo la acción la principal actividad política

7 Resaltado del autor. 
de los seres humanos (Arendt, 1997, p. 151). En este sentido, la filósofa y politóloga alemana ha legado una propuesta crítica $y$, hasta cierto punto, revolucionaria. Arendt, al desafiar al pensamiento político imperante, que concibe el poder como la posibilidad de imponer en cada caso la propia voluntad al comportamiento de los demás, está cuestionando también las concepciones violentológicas de las identidades: las identidades basadas en grupos; esas que aparentemente dan seguridad y estabilidad (Taylor, 1996) bajo una falsa capa de fortaleza. Michael Mann abunda en el maridaje entre paz e identidad, al destacar el carácter colectivo del poder mediante el ejercicio de la cooperación y la creación de redes (Mann, 1991, p. 21) en pos de un bien común, que no impide o limita el desarrollo de las capacidades de otras entidades humanas. No obstante, este mismo autor nos advierte que las formas violentas de ejercicio del poder y de creación de identidades actúan simultáneamente y están entrelazadas.

Desde la perspectiva de la investigación para la paz, el poder emerge como la capacidad que detentan todas las entidades humanas para transformar la realidad y tomar las riendas de sus propias existencias (Jiménez Arenas, 2020). Este guiar la propia vida es, en sí mismo, un planteamiento radical de la identidad, puesto que invita a la acción, al ejercicio de la agencia, ya que el poder es también poder-hacer (Martínez Guzmán, 2001; Holloway, 2005, p. 32 y ss.; Stussi, 2017, p. 33). Además, para disminuir la importancia a las concepciones esencialistas de los seres humanos y de las identidades, resulta fundamental que estas se construyan sobre la base de lo que hacemos y no solo de lo que somos. Porque solo desde el reconocimiento de que todas las entidades tenemos capacidad para hacer las paces, podemos pedirnos cuentas (Martínez Guzmán, 2001).

Holloway (2005, p. 32 y ss.) plantea que, junto al poder-hacer, también existe el poder-sobre. Ahora bien, este no sería poder en el sentido arendtiano del concepto, sino que formaría parte de la violencia. Por lo tanto, un poder, una identidad, que no permita o limite la capacidad de agencia (Brown, 2017; Currie et al., 2010; Skovgaard-Smith et al., 2019; Ybema et al., 2009) forma parte de la violencia.

Las identidades modernas se nutren de la creencia en que la aceptación de los componentes éticos, morales y conductuales de estas se basan en una mera 
transferencia, que debe ser aceptada de manera acrítica por los miembros que constituyen un determinado grupo (Dugas y Kruglanski, 2018). No obstante, el poder-hacer de Holloway (2005) nos lleva, como ya se ha comentado, al ejercicio, a la agencia de la paz, a la acción, como paso más allá del empoderamiento pacifista (Londoño Valencia et al., 2017).

Siguiendo a Malmström, la agencia es la capacidad humana para actuar — obviamente, otras especies vivas son animadas y, por lo tanto, actúan-; el hecho diferencial humano es que está socioculturalmente mediada (Malmström, 2012, p. 24). Dicho de otra manera, las capacidades personales (también colectivas) para sentir, pensar, meditar, intentar y actuar en las relaciones sociales particulares interaccionan con los contextos históricos en los que los agentes viven sus vidas (Mahmood, 2006, p. 54). La cuestión clave es que los contextos, actuando de manera violenta, mutan el poder-hacer en poder-sobre (Holloway, 2005), cercenando la capacidad de agencia y tratando de evitar que se habitúen —en el sentido bourdiano- a actuar.

Desde el ejercicio de la hegemonía se tiende a plantear que la construcción de las identidades corresponde a una élite dominadora que, mediante sus prácticas, fuerzan a los dominados a aceptar su rol pasivo (Gramsci, 1991). No obstante, la historia no solo la escriben los vencedores, también puede ser considerada una tecnología de la identidad encaminada a la transformación social (Jiménez-Arenas, 2018, p. 26).

\section{IDENTIDADES CALEIDOSCÓPICAS Y AMALGAMAS}

A lo largo de páginas anteriores hemos visto cómo las identidades interaccionan con la ontología y el poder, de tal forma que acaban por retroalimentarse. Ambos son conceptos clave para la filosofía y las ciencias políticas. No obstante, mi formación como historiador me lleva a desarrollar la idea expuesta en el último párrafo del capítulo anterior: la disciplina de la historia como tecnología de la identidad orientada a la transformación social. 
¿Por qué una tecnología?

Para Aristóteles lo que tenían en común la tragedia y la pintura en tanto que imitaciones no las distingue, en cuanto a sus procedimientos, de artes tales como la fabricación de zapatos o la medicina. Por ofensivo que pueda parecer esto a nuestra sensibilidad posromántica, Aristóteles creía que el artista/artesano se hace con una materia en bruto (un carácter, un cuero) y usa una serie de ideas y procedimientos (la trama o la forma de un zapato) para producir algo (una tragedia, unos zapatos). (Shiner, 2004, p. 47)

En el caso del historiador, la materia bruta sería las fuentes históricas (entre las que se incluyen, obviamente, las materiales, las arqueológicas); las ideas y los procedimientos incluirían el andamiaje teórico-metodológico del que nos valemos para la interpretación histórica; y el resultado sería la narración histórica. Pero también uso tecnología en un sentido más reciente: la historia y la identidad, como ciencia básica y como ciencia aplicada, respectivamente, son interdependientes. Ahora bien, al contrario de lo que ocurre con otras ciencias y otras tecnologías, la historia y las identidades son interpeladas por otros especialistas. No obstante, y quizás por ello, son tantos los que pretenden participar en su configuración, que las identidades, o las relaciones de pertenencia, están omnipresentes.

Las formas de pertenencia dependerán pues, aunque no solo, del enfoque que adoptemos cuando llevamos a cabo la práctica profesional de la disciplina de la historia. Desde nuestra particular forma de entenderla, apostamos, como ya hemos comentado, por la paz imperfecta y el giro epistemológico. Así, es relevante visibilizar todos los ejemplos de tiempos, espacios y agentes de transformación pacífica de los conflictos a lo largo de la historia; en definitiva, poner en valor la historia de la paz (Muñoz Muñoz y Beatriz Molina Rueda, 1998; Muñoz Muñoz y López Martínez, 2000; Muñoz Muñoz, 2001; Muñoz Muñoz y Pérez Beltrán, 2003; Bolaños Carmona y Muñoz, 2011; Jiménez Arenas, 2011; Jiménez Arenas y Muñoz Muñoz, 2013; Alfaro Pareja, 2014; Jiménez Arenas, 2015; Alfaro Pareja, 2016; Muñoz Muñoz y Jiménez Arenas, 2015; Jiménez Arenas, 2018) como materia bruta y trama para la construcción de identidades basadas en narrativas históricas pacíficas. 
En el apartado introductorio puse de manifiesto cómo las concepciones tradicionales de las identidades no se avienen bien, conque la mayor parte de los conflictos en los que se han visto envuelto los humanos se han transformado de manera pacífica (Muñoz, 2001). Partiendo de la paz imperfecta y el giro epistemológico, propongo la doble metáfora de la amalgama y el caleidoscopio como alternativa para la configuración de identidades. La primera destaca porque a partir de estructuras formales se aglutinan conceptos o contenidos significativos y diversos en una sola forma. La segunda porque se generan formas complejas a partir de la interacción dinámicas de diferentes componentes.

Como adelanté, las identidades son construcciones sociales que se pergeñan dentro de un marco sistémico para condicionar los roles mediante los cuales los diferentes actores y las diferentes actrices orientan sus representaciones y sus acciones. Esto nos permite resaltar que el carácter excluyente, jerárquico y estanco no es consustancial a las identidades. Ocurre que muchas construcciones identitarias beben directamente de la tríada de la mística masculina planteada por Myriam Medziam (1996, p. 22): the best, the boss, the one. Las identidades asesinas de las que habla Maalouf (2001) tienen mucho de autorreconocimiento como los mejores, los jefes y los únicos. No solo son excluyentes, sino que contribuyen a la creación de la imagen del enemigo como otro al que hay que destruir. La lógica belicista incorporada por la masculinidad guerrera se convierte en violencia metaestructural por ser independiente de un sistema socioeconómico concreto (Jiménez Arenas, 2018, pp. 29-30). Las identidades nacionales se nutren, y en la actualidad hay un repunte importante del ala más dura de los discursos androcéntricos de la realidad. Ambos, identidad nacional y discursos androcéntricos, se retroalimentan para crear corazas protectoras con la ficticia seguridad que nos dan las narrativas directas, simplistas, antagónicas, acríticas y polarizadoras, creadoras de estereotipos y discriminantes, monolíticas e incuestionables, y que comparten, en mayor o menor medida, muchas de las características de la propaganda propuesta por Joseph Goebbels (Doob, 1950). El momento crítico que se vive durante la primavera de 2020 está contribuyendo al conservadurismo, garante de una presunta confianza (Taylor, 1996, p. 16) que está en entredicho, que solo puede ser juzgada por miembros con el mismo rango (Taylor, 1996, p. 18) y que se alimenta de la lógica del enemigo. 
Como alternativa, desde la investigación para la paz proponemos identidades que partan de la consideración positiva e inevitable del cambio (Rodríguez Magda, 2011, p. 6), que permitan considerar la crisis como una oportunidad para la creatividad y la renovación continua (Muñoz, 2001, p. 36), y que vislumbren futuros transformados en aras del desarrollo de las capacidades humanas deseables.

No se trata de definir las identidades a través de otros significativos, como propone Taylor (1996, p. 13), ni como una acumulación de identidades estancas de las cuales elijo la que más me interesa resaltar en un momento dado (Hobsbwam, 1994, p. 5). Tampoco se trata del reconocimiento de los otros desde la perspectiva del yo (Cucagna et al., 2007), ni exclusivamente a través de la incorporación de la interseccionalidad, concepto tremendamente fértil pero preñado de marginación (Crenshaw, 1991). Por ende, desde la paz imperfecta y el giro epistemológico debemos ir más allá. Para ello nos valdremos, como ya hemos comentado, de dos metáforas: la amalgama y los caleidoscopios.

Maalouf (2001) marcó un camino: no se puede definir a las identidades a partir de los elementos que las constituyen. De esta forma, se adelanta a lo que nosotros consideramos identidades amalgama. Esto es, aquellas que se constituyen a partir de la interacción, la mezcolanza, y cuyo resultado es diferente al de la suma de las partes; identidades espurias tan propias de unos humanos que, desde nuestro origen, somos cyborgs — esto es, híbridos con máquinas—. Lo interesante es que no somos ni humanos ni máquinas, y buena prueba de ello es la manera como dicho maridaje transforma nuestras relaciones sociales (Haraway, 1995) e, incluso, nuestras oportunidades de supervivencia.

Efectivamente, los humanos actuales no somos sino el fruto del mestizaje, del flujo genético. Neandertales y denisovanos ${ }^{8}$ nos han ayudado a sobrevivir fuera del lugar de nuestro origen. Dicha hibridación o, más bien, flujo genético fue negado por la mayoría de investigadores(as) en la evolución humana. Por ello, el paradigma dominante hasta 2010 era la hipótesis del reemplazamiento: por donde

8 Taxones diferentes a los denominados Homo sapiens (los nosotros). 
iba dispersándose el Homo sapiens, las especies preexistentes iban desapareciendo. La lógica imperante era la de los exterminios (criticada extensamente en Jiménez Arenas, 2018, p. 26). No obstante, la secuenciación del ADN neandertal, junto a la de los denisovanos, puso de manifiesto la prolija historia de interacciones que nuestro pasado no lega. Es más, ese trasvase, ese los otros, contribuyó, y sigue contribuyendo, a que los recién llegados ${ }^{9}$ — los nosotros, los etnocéntricos europeos y sus descendientes americanos- pudiéramos hacer frente a los virus propios de estas latitudes (Enard y Petrov, 2018). Los neandertales no se extinguen, perviven en nosotros.

Otro ejemplo, actual en este caso, y más directamente relacionado con la paz, es el himno nacional de Sudáfrica, el cual se ha convertido en actos de mediación y reconciliación gracias a su carácter híbrido que, entre otras características, incorpora versos en las lenguas xhosa, zulú, sesotho, afrikáans e inglés (Coplan y Jules-Rosette, 2005). De ahí la importancia de redefinir los símbolos, sobre todo en sociedades que han vivido conflictos con un alto grado de fragmentación y segregación, generadores de violencias extremas. Ahora bien, la metáfora de la amalgama no da cuenta del dinamismo, del carácter procesual, de la condición inacabada e imperfecta de las identidades. Para eso, debemos recurrir a las identidades caleidoscópicas.

Un caleidoscopio es un artilugio que a partir de fragmentos de diferentes tamaños, formas y colores conforma figuras complejas. Las identidades caleidoscópicas dan cuenta de las continuas transformaciones que acontecen a lo largo de las vidas de las entidades humanas. Son cambiantes ontogenéticamente ${ }^{10}$ hablando. Otra característica de las identidades caleidoscópicas es que conviven aspectos que tradicionalmente se han considerado antagónicos, puesto que las identidades se han

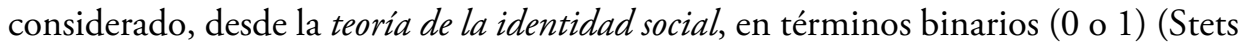
y Burke, 2000, p. 229).

Nosotros, desde la investigación para la paz, le apostamos a la contribución de la teoría de la identidad que presenta toda una gama de posibilidades (Stets y Burke,

9 Es importante tomar en consideración que nuestra especie, Homo sapiens, se origina en África y desde su territorio de nacimiento se dispersa por toda la Tierra a partir de diferentes oleadas.

10 Ontogenia es la parte de la biología que se dedica al estudio del origen y desarrollo de un organismo. 
2000, p. 229). De esta forma, nuestra identidad puede estar configurada a partir de fragmentos nacionales diferentes en función de las experiencias vitales y grupales de los individuos en cuestión. Así, es posible sentirse español sin excluir como lo colombiano ha ejercido una influencia importante. Ya no se trata, como proponía Maalouf, de identidades heredadas, sino de identidades creadas, no por agregación, sino por interacción, en la que el otro se inserta en el mismo gesto en y desde uno mismo (Madrid, 2008, p. 112). Ocurre algo similar con las identidades basadas en los complejos sexo-género. Yendo un punto más allá de la célebre frase de Simone de Beauvoir, citada en la introducción, los hombres también podemos llegar a ser mujeres en el sentido de incorporar formas de estar y de actuar que tradicionalmente se han considerado femeninas ${ }^{11}$ y que, sin embargo, como ocurre con los cuidados, entran en la esfera de la ética y, por lo tanto, es una corresponsabilidad de todas las entidades humanas (Comins Mingol, 2009). Esto nos da pie a recordar la peligrosidad de las identidades basadas en la naturalización de los comportamientos humanos, del esencialismo que genera violencia metaestructural y que troca la diferencia en desigualdad (Jiménez Arenas, 2018, p. 29-30).

Abundando en la idea de caleidoscopio, alguno de los fragmentos que son relevantes para una identidad concreta provienen de colectivos que han sido marginalizados y vulnerabilizados. Es el caso de la población gitana en Espańa. Si nos preguntamos por una música identificativa de lo español, enseguida brota en nuestra mente imágenes relacionadas con el flamenco; estas músicas de origen aún incierto, pero que pudiera ser permanencia de tradiciones enraizadas de los moriscos ${ }^{12}$ (Manuel, 2018). Lo paradójico es que el nosotros está constituido sustancial e inherentemente por el otro rechazado, renegado y al que incluso tratamos de eliminar. Eliminándolos a ellos, estamos perdiendo nuestra existencia.

Es cierto que, para el caso concreto del flamenco, se puede plantear la cuestión de la apropiación cultural, del uso partidista y estigmatizante de una determinada práctica cultural por parte de una élite hegemónica (de Santiago Ortega, 2018). Pero no es

11 El énfasis es nuestro para remarcar que no se trata de una afirmación nuestra.

12 Islámicos(as) forzados(as) a convertirse al cristianismo y, tras diferentes represiones, obligados a abandonar sus tierras en Castilla y Aragón. 
menos cierto que, desde la perspectiva del giro epistemológico y ontológico como acto de justicia, debemos reconocer el papel fundacional y constituyente de lo gitano en lo español. Por lo tanto, reivindicamos la importancia de los que ahora marginamos a través del reconocimiento del papel de las(os) otras(os) en los(as) nosotros(as). Esta misma idea es extensiva al papel desempeñado por las culturas ancestrales americanas en la identidad española. Esto lo veremos a través del ejemplo de la gastronomía.

Tres platos con los que se reconoce internacionalmente a la comida española son la paella, el gazpacho y, por supuesto, la tortilla de patatas. Olvidemos la primera, ya que el origen de su ingrediente principal es foráneo (para España), puesto que el arroz proviene del sudeste asiático. Los componentes principales del segundo y el tercero son respectivamente el tomate y la patata, ambos de procedencia americana (Sato et al., 2012; Ames y Spooner, 2018). A pesar de ello, gracias a la interacción cultural se han convertido en parte consustancial de la identidad y la cultura españolas; de nuevo, la presencia de las(os) otras(os) como elementos consustanciales del nosotras(os). La gastronomía pasa a ser, por mor de los intercambios, gastrono-nuestra.

\section{ConClusiones}

Del diálogo de la paz imperfecta, el giro ontológico y las identidades se colige que, en la mayor parte de los casos, estas son procesuales, inacabadas, en permanente construcción y responsabilidad de todas las entidades humanas. No obstante, para visibilizar esta caracterización de las identidades debemos introducir una profunda reflexión sobre el concepto de poder y de agencia. El poder, entendido como imposición, deja de serlo para convertirse en violencia (Arendt, 1970). Por ello, es fundamental subrayar identidades o aspectos de estas que se basan en el consenso (Stets y Burke, 2000); en la participación del mayor número posible de agentes. Porque siendo agentes nos convertimos en parte de la acción y, por lo tanto, en corresponsables de lo común.

Por otra parte, el punto de partida de las identidades, consideradas como fundamento del ser de lo ente (Heidegger, 2016), debemos buscarlo en el conflicto (Millán 
Campuzano, 2015). De hecho, las relaciones de pertenencia — lejos de la presunta estaticidad y pureza promulgada por los defensores de las identidades basadas en, por ejemplo, el nacionalismo excluyente y el androcentrismo acérrimo- son cambiantes y adoptan rasgos que son propios de los otros. Estos, a menudo, han sido marginalizados o sepultados por los grupos hegemónicos que dictan lo que es y lo que no es para un determinado colectivo.

Así las cosas, podemos plantear que las identidades, como parte de la cultura, comparten con esta que no solo se pueden percibir lógicas de exterminio, de aculturación total hasta hacer desaparecer las costumbres de aquellos grupos humanos considerados culturalmente inferiores (McGee, 1896). También, y mayoritariamente, como se viene planteando desde la primera mitad del siglo pasado, el contacto entre diferentes poblaciones provoca cambios culturales, entre los cuales se incluyen los identitarios, en ambos (Redfield, Linton y Herskovits, 1936). Las identidades no son ni estáticas ni puras; ni apocalípticas ni integradas; tampoco solo excluyentes y, por ende, violentas. Son complejas - paradójicas - y rizomáticas, donde lo conectivo gana protagonismo; tienen en cuenta lo estructural, aunque sin obviar la capacidad de agencia; por ello debemos construir las identidades sobre lo que nos hacemos (Martínez Guzmán, 2001; Holloway, 2005). También son fruto de los contactos, los trasvases, el movimiento y el desarrollo de las capacidades deseables de las entidades humanas.

Como planteé en un trabajo publicado en 2011, es fundamental:

El reconocimiento de los comportamientos altruistas, cooperativos y filantrópicos (hoy considerados pacíficos) de nuestros antepasados, que han sido fundamentales para los sucesivos éxitos evolutivos de nuestra familia porque han contribuido al desarrollo de las potencialidades [capacidades] humanas, las del pasado y las del presente, y que, ante la vorágine violentológica, es necesario recuperar porque también contribuyen a performar nuestra identidad pacífica. (Jiménez Arenas, 2011, p. 93).

Las identidades son imperfectas, adaptadas y promotoras del cambio hacia mundos más justos, dignos y pacíficos. 


\section{Agradecimientos}

Este trabajo se ha llevado a cabo gracias al apoyo del Grupo de Investigación HUM-607 de la Junta de Andalucía.

\section{REFERENCIAS}

Alfaro Pareja, F. (2014). Capacidades para la paz en las negociaciones para el reconocimiento de la Independencia de Venezuela por parte de España (1833 y 1846). Revista de Paz y Conflictos, 7, 175-194.

Alfaro Pareja, F. (2016). La historia oculta de la Independencia de Venezuela: De la guerra idealizada a la paz imperfecta. Caracas: Editorial Alfa.

Ames, M. y Spooner, D. M. (2008). DNA from herbarium specimens settles a controversy about origins of the European potato. American Journal of Botany, 95(2), 252-257.

Arendt, H. (1970). Sobre la violencia. México: Joaquín Mortiz.

Arendt, H. (1997). ¿Qué es la politica? Barcelona: Paidós.

Baudrillard, J. (1978). Cultura y simulacro. Barcelona: Kairós.

Beauvoir, S. de (2005). El segundo sexo. Madrid: Cátedra / Universitat de València.

Bolaños Carmona, J. y Muñoz, F. A. (eds.). Los habitus de la Paz. Teorías y prácticas de la paz imperfecta. Granada: Editorial de la Universidad de Granada.

Bourdieu, P. (1972). Esquisse d'une théorie de la pratique. Précédé de "Trois études d'ethnologie kabyle". Ginebra: Droz.

Bourdieu, P. (1991). Language and symbolic power. Oxford: Polity Press. 
Brown, A. D. (2017). Identity work and organizational identification. International Journal of Management Reviews, 19(3), 296-317.

Comins Mingol, I. y Jiménez Arenas, J. M. (2019). Reflexiones filosófico-antropológicas en torno al cuidado como origen y fundamento de la justicia. En P. A. Cabello Tijerina, G. Díaz Pérez y R. L. Vázquez Gutiérrez (eds.), Investigación para la Paz: Teorias, prácticas y nuevos enfoques (pp. 82-103). Valencia: Tirant lo Blanc.

Comins Mingol, I. (2009). Filosofía del cuidar. Barcelona: Icaria.

Coplan, D. B. y Jules-Rosette, B. (2005). Nkosi Sikelel' iAfrika and the liberation of the spirit of South Africa. African Studies, 64(2), 285-308.

Crenshaw, K. (1991). Mapping the margins: Intersectionality, identity politics, and violence against women of color. Stanford Law Review, 43(6), 1241-1299.

Cucagna, A., Leñero, M., Casillas, A. y Armengol, L. (2007). En torno a la alteridad. En A. M. Martínez de la Escalera (coord.), Estrategias de resistencia (pp. 5965). México: Programa Universitario de Estudios de Género.

Currie, G., Finn, R. y Martin, G. (2010). Role transition and the interaction of relational and social identity: New nursing roles in the English NHS. Organization Studies, 31(7), 941-961.

Davis, A. (1981). Mujeres, raza y clase. Madrid: Akal.

De Santiago Ortega, P. P. (2018). Flamenco: de la marginalidad social a la referencia cultural pasando por la apropiación política. Revista de Investigación sobre Flamenco 'La Madrugá', 15, 91-115.

Derrida J. (1997). El tiempo de una tesis. Deconstrucción e implicaciones conceptuales. Barcelona: Ediciones Proyecto.

Doob, L. W. (1950). Goebbels' principles of propaganda. Public Opinion Quarterly, 14(3), 419-442. 
Dugas, M. y Kruglanski, A. W. (2018). Shared reality as collective closure. Current Opinion in Psychology, 23, 72-76.

Eco, U. (1996). Apocalípticos e integrados. Barcelona: Lumen.

Enard, D. y Petrov, D. A. (2018). Evidence that RNA Viruses Drove Adaptive Introgression between Neanderthals and Modern Humans. Cell, 175(2), 360-371.

Ferrater Mora, J. (2001). Ontología. En J. Ferrater Mora (coord.), Diccionario de Filosofía vol. 3 (pp. 2622-2628). Barcelona: Círculo de Lectores (nueva edición revisada, aumentada y actualizada por J. M. Terricabas, bajo la supervisión de P. Cohn Ferrater Mora).

Fisas, V. (1998). Cultura de paz y gestión de conflictos. Barcelona: Icaria.

Foucault, M. (1980). Microfisica del poder. Madrid: Ediciones de la Piqueta.

Foucault, M. (1988). El sujeto y el poder. Revista Mexicana de Sociología, 50(3), 3-20.

Galtung, J. (1990). Cultural Violence. Journal of Peace Research, 27(3), 291-305.

Garcés Montoya, A. P. (2005). Nos-otros los jóvenes: polisemias de las culturas y los territorios musicales en Medellín. Medellín: Sello Editorial Universidad de Medellín.

Gibernau, M. (2017). Identidad. Pertenencia, solidaridad y libertad en las sociedades modernas. Madrid: Trotta.

Gramsci, A. (1991). Escritos politicos (1917-1933). México: Siglo XXI.

Heidegger, M. (2016). Identidad y diferencia. Revista de Filosofía, 21, 5-54. Recuperado de https://revistafilosofia.uchile.cl/index.php/RDF/article/view/44529/46555

Hernández Castellanos, D. A. (2011). Formas de alteridad: Un reto epistemológico y político. Andamios, 8(16), 11-31. 
Hobsbwam, E. J. (1994). Identidad. Revista Iberoamericana de Filosofía Politica, 3, 5-17.

Holloway, J. (2005). Cambiar el mundo sin tomar el poder. El significado de la revolución hoy. Caracas/Valencia: Vadell Hermanos Editores. Recuperado de https://ilusionismosocial.org/pluginfile.php/601/mod_resource/content/3/cambiar-el-mundo-el-poder-1275850.pdf

Iza Certuche, M. (2018). Interseccionalidad y construcción de paz territorial en Colombia: análisis desde el caso de las mujeres de Buenaventura. Ciudad Paz-ando, 11(2), 16-28.

Jiménez Arenas J. M. y Muñoz Muñoz, F. A. (eds.). (2013). La Paz, partera de la Historia. Granada: Editorial de la Universidad de Granada.

Jiménez Arenas, J. M. (2011). Pax Homínida. Una aproximación imperfecta a la evolución humana. En J. Bolaños Carmona y F.A. Muñoz (eds.), Los habitus de la Paz. Teorías y prácticas de la paz imperfecta (pp. 65-93). Granada: Editorial de la Universidad de Granada.

Jiménez Arenas, J. M. (2015). Complexity, cooperation and childhood: An evolutionary perspective. En M. Sánchez Romero, E. Alarcón García y G. Aranda Jiménez (eds.), Children, spaces and identity (pp. 26-39). Oxford: Oxbow.

Jiménez Arenas, J. M. (2018). Evolución humana y paz. Una aproximación desde la teoría y la práctica. Vinculos de Historia, 7, 15-36.

Jiménez Arenas, J. M. (2020). De la paz imperfecta a la agencia pacifista. Revista de Historia de la Educación Latinoamericana, en prensa.

Keddell, E. (2009). Narrative as identity: Postmodernism, multiple ethnicities, and narrative practice approaches in social work. Journal of Ethnic \& Cultural Diversity in Social Work, 18, 221-241.

Locke, J. (2013). Ensayo sobre el entendimiento humano; Escritos sobre la tolerancia; Pensamientos sobre la educación. Madrid: Editorial Gredos. 
Luyckx, K., Soenens, B. y Goossens, L. (2007). The personality-identity interplay in emerging adult women: convergent findings from complementary analyses. European Journal of Personality, 20(3), 195-215.

Maalouf, A. (2001). In the name of identity. Violence and the need to belong. Nueva York: Arcade Publishing.

Madrid, R. (2008). Hacia una ética de la responsabilidad: Derrida y el otro "por venir" en Lévinas. Sapientia, 63(223), 105-141.

Mahmood, S. (2006). Feminist theory, agency, and the liberatory subject: Some reflections on the Islamic revival in Egypt. Temenos, 42(1) (2006), 31-71.

Malmström, M. F. (2012). Gender, agency, and embodiment theories in relation to space. Egypt/Monde Arab, 9 [Gouvernance locale dans le monde arabe et en Méditerranée: Quel rôle pour les femmes? editado por Sylvette Denèfle y Safaa Monqid], 21-35.

Mann, M. (1991). Las fuentes del poder social, vol. 1. Madrid: Alianza.

Manuel, Antonio (2018). Flamenco. Arqueologia de lo Jondo. Córdoba: Almuzara.

Martínez Fernández, G. y Jiménez Arenas, J. M. (2003). Los humanos prehistóricos ni pacíficos ni violentos por naturaleza sino todo lo contrario. En F. A. Muñoz y C. Pérez Beltrán (eds.), Experiencias de Paz en el Mediterráneo (pp. 59-126). Granada: Editorial de la Universidad de Granada.

Martínez Guzmán, V. (2001). Filosofía para hacer las paces. Barcelona: Icaria.

McGee, W. J. (1898). Piratical acculturation. American Anthropologist, 11, 243-249.

Medziam, M. (1996). Chicos son, hombres serán. Cómo romper los lazos entre masculinidad y violencia. Madrid: Horas y Horas. 
Millán Campuzano, M. A. (2015). Hermenéutica de la paz y los conflictos. Cuautitlán Izcalli: E-dae.

Morin, E. (1998). Introducción al pensamiento complejo. Barcelona: Gedisa.

Morin, E. (2004). La identidad humana. El Método V. La humanidad de la humanidad. Barcelona: Círculo de Lectores.

Muñoz Muñoz, F. (ed.). (2001). La paz imperfecta. Granada: Editorial de la Universidad de Granada.

Muñoz Muñoz, F. A. y Jiménez Arenas, J. M. (2015). Histoire et recherche pour la paix. Expériences atour la Meditérranée. Cahiers de la Mediterranée, 91, 165-178.

Muñoz Muñoz, F. A. y López Martínez, M. (eds.). (2000). Historia de la paz: tiempos, espacios y actores. Granada: Editorial de la Universidad de Granada.

Muñoz Muñoz, F. A. y Molina Rueda, B. (2010). Una cultura de paz compleja y conflictiva. La búsqueda de equilibrios dinámicos. Revista de paz y conflictos, 3, 44-61.

Muñoz Muñoz, F. A. y Molina Rueda, B. (eds.). (1998). Cosmovisiones de Paz en el Mediterráneo antiguo y medieval. Granada: Editorial de la Universidad de Granada.

Muñoz Muñoz, F. A. y Pérez Beltrán, C. (eds.). (2003). Experiencias de Paz en el Mediterráneo. Granada: Editorial de la Universidad de Granada.

Redfield, R., Linton, R. y Herskovits, M. J. (1936). Memorandum for the study of acculturation. American Anthropologist, 38, 149-152.

Renan, E. (2001). ¿Qué es una nación? Madrid: Sequitur.

Rodríguez Magda, R. M. (2007). Transmodernidad: La globalización como totalidad transmoderna. Revista Observaciones Filosóficas, 4. Recuperado de www.observacionesfilosoficas.net/latransmodernidadlaglo.html 
Rodríguez Magda, R. M. (2011). Transmodernidad: un nuevo paradigma. Transmodernity: Journal of Peripheral Cultural Production of the Luso-Hispanic World, 1, 1-13.

Ruelle, D. (1993). Azar y caos. Madrid: Alianza.

Sánchez Cazorla, J. (1997). Ciencia y tecnología para la paz. En F. J. Rodríguez Alcázar, R. M. Medina Doménech, y J. A. Sánchez Cazorla (eds.), Ciencia, tecnología y sociedad. Contribución para una cultura de paz (pp. 15-47). Granada: Editorial de la Universidad de Granada.

Sato, S., Tabata, S., Hirakawa, H., ... Tomato Genome Consortium. (2012). The tomato genome sequence provides insights into fleshy fruit evolution. Nature, 485(7400), 635-641.

Skovgaard-Smith, I., Soekijad, M. y Down, S. (2019). The Other side of 'us': Alterity construction and identification work in the context of planned change. Human Relations, https://doi.org/10.1177/0018726719872525

Stets, J. E. y Burke, P. J. (2000). Identity Theory and Social Identity Theory. Social Psychology Quarterly, 63(3), 224-237.

Stussi García, M. (2017). El poder y las respuestas ciudadanas de compensación de asimetrias. Estudio sobre el concepto del poder y su importancia en el desarrollo de iniciativas ciudadanas en la ciudad de Granada para la transformación social hacia una sociedad más pacifica (tesis inédita de maestría). Universidad de Granada, Granada, España.

Valencia Londońo, P. A., Pérez-Gallart Mingrone, S. y Mancera González, O. (eds.). (2017). Empoderamiento pacifista. Medellín-Granada: Sello Editorial de la Universidad de Medellín-Editorial de la Universidad de Granada.

Vila, P. (2001). Música e identidad. La capacidad interpeladora y narrativa de los sonidos. En A. M. Ochoa Gautier y A. Gragnolini (eds.), Cuadernos de Nación. Músicas en transición. Bogotá: Ministerio de Cultura, 15-44.

Ybema, S., Keenoy, T., Oswick C., Beverungen, A., Ellis, N. y Sabelis, I. (2009). Articulating identities. Human Relations, 62(3), 299-322.

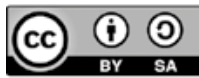

